\title{
Critical Update on Malignant Salivary Gland Neoplasms
}

\author{
Natalya Chernichenko
}

\begin{abstract}
Salivary gland neoplasms are relatively rare tumors with a wide range of biologic behavior. Early low-grade malignancies could be adequately treated with surgery alone, while larger locally advanced tumors will require adjuvant radiation therapy. The role of chemotherapy remains palliative. The goal of this article is to provide a critical review of recent literature on diagnosis and management of salivary neoplasms.
\end{abstract}

Keywords: Head and neck cancer, Perineural invasion, Salivary neoplasm.

How to cite this article: Chernichenko N. Critical Update on Malignant Salivary Gland Neoplasms. Int J Head Neck Surg 2017;8(2):71-75

Source of support: Nil

Conflict of interest: None

\section{INTRODUCTION}

Salivary gland carcinomas are relatively rare malignant tumors, accounting for less than $5 \%$ of all cancers of the head and neck. ${ }^{1}$ Tumors can arise in major salivary glands: Parotid, submandibular, and sublingual, and minor salivary glands. They encompass a wide spectrum of histologic abnormalities with a wide range of biologic behavior. In fact, histologically salivary gland tumors represent the most heterogeneous group of tumors in the body. ${ }^{2}$ Etiology of salivary neoplasms is not very well understood. Exposure to ionizing radiation ${ }^{3,4}$ and occupational exposure, such as woodworking, manufacturing of the rubber products, and plumbing, ${ }^{5,6}$ has been implicated. Salivary gland tumors usually present with enlarging mass, which may be associated with neurological symptoms, such as pain, paralysis if motor nerve is involved, or numbness if sensor nerve is involved. Clinical features suspicious for malignancy include nerve paralysis, rapid enlargement of the mass, pain, tumor fixation to surrounding structures, and cervical lymphadenopathy. Prognostic factors relating to the patient, cancer grade and stage, and management account for variability in cure rates.

Chief and Assistant Professor

Department of Head and Neck; Department of Otolaryngology SUNY Downstate Medical Center, Brooklyn, New York, USA

Corresponding Author: Natalya Chernichenko, Chief and Assistant Professor, Department of Head and Neck; Department of Otolaryngology, SUNY Downstate Medical Center, Brooklyn New York, USA, Phone: 7182701638, e-mail: natalya. chernichenko@downstate.edu

\section{HISTOLOGY}

A clear relationship between histologic types and biologic aggressiveness is often lacking. ${ }^{7}$ The World Health Organization histologic classification of salivary gland malignant neoplasms subdivides these tumors in three broad categories: Low-, intermediate-, and high-grade groups. Acinic cell carcinoma, polymorphous low-grade carcinoma, and low-grade mucoepidermoid carcinoma are classified as low-grade tumors. Adenoid cystic carcinoma and epithelial myoepithelial carcinoma are considered intermediate grade tumors. Finally, high-grade mucoepidermoid carcinoma, salivary duct carcinoma, carcinoma ex-pleomorphic adenoma, adenocarcinoma not otherwise specified, and undifferentiated carcinomas are classified as high-grade tumors. When making clinical decisions regarding management of salivary gland malignancies, intermediate-grade tumors are frequently grouped with high-grade tumors. However, clinical grade does not always parallel biologic aggressiveness, response to therapy, and prognosis. In such a way, traditionally low-grade acinic cell carcinoma can demonstrate an aggressive high-grade subtype with a poor prognosis. ${ }^{8}$ Similarly, myoepithelial carcinomas had been described to exhibit a wide spectrum of cytomorphologic features and diverse clinical outcomes. ${ }^{9}$ Moreover, grading shows poor interexaminer reproducibility and therefore, independent prognostic power is low. ${ }^{10,11}$ More precise grading systems have been developed for three most common salivary tumors: Mucoepidermoid carcinoma, ${ }^{12}$ acinic cell carcinoma, ${ }^{13}$ and adenoid cystic carcinoma. ${ }^{14}$

\section{DIAGNOSTIC EVALUATION}

The importance of thorough evaluation of salivary neoplasms cannot be overemphasized. Accurate history and physical examination is essential in the initial evaluation of suspected salivary gland neoplasm. Stigmata of malignancy includes rapid growth, fixed mass, pain, paralysis of a motor nerve, impairment in a sensory nerve distribution, skin involvement, and nodal metastasis. Nonetheless, it is uncommon for salivary neoplasm to present with asymptomatic mass. ${ }^{15}$

The utility of fine-needle aspiration (FNA) remains controversial in the evaluation of salivary gland lesions. Those that disagree with tissue diagnosis before surgery suggest that extent of surgery and decision regarding management of facial nerve are made based on 
intraoperative findings rather than results of the FNA. Fine-needle aspiration of the salivary gland mass can be particularly useful in evaluating a poorly defined mass in order to confirm clinical suspicion of malignancy and appropriately counsel the patient preoperatively, especially if facial nerve paresis or paralysis is anticipated. Fine-needle aspiration has a relatively low sensitivity in diagnosing salivary malignancy, but appears to be fairly specific in the range of 84 to $100 \%{ }^{16}$ The reported values are broad, which is likely due to variability in technique and experience of cytopathologist. Of course if FNA shows lymphoma, surgery is not indicated; however, lymphocyte-predominant FNA specimens have a low predictive value and cannot reliably identify low-grade lymphoma. ${ }^{16}$ It is important to note that negative FNA does not rule out malignancy and should not supersede clinical judgment in the management of suspected malignancy.

While imaging of suspected salivary gland tumors cannot definitively differentiate benign and malignant tumors, ${ }^{17}$ its main role is to define the extent of the disease. Cross-sectional imaging with computed tomography (CT) scan and/or magnetic resonance imaging (MRI) is essential in treatment planning and determining the surgical resectability. Computed tomography scan allows accurate assessment of tumors extending into bony structures, such as mandible, hard palate, and temporal bone. Computed tomography scan should be performed with contrast, as it will give better information about the soft tissue definition of the disease and help the surgeon preoperatively and intraoperatively, making critical decisions regarding tumor excision. Magnetic resonance imaging with and without contrast is helpful in evaluating deep lobe vs parapharyngeal space tumors, skull base and intracranial extension and, most importantly, cranial nerve invasion. Computed tomography and MRI provide complimentary information, and, therefore, in most cases of suspected malignant salivary gland neoplasm, both studies are recommended. Positron emission tomography (PET)/CT shows low accuracy in differentiating benign vs malignant pathology, as certain benign tumors, such as pleomorphic adenoma and Wartin's tumor are fluorodeoxyglucose-avid. ${ }^{18}$ Positron emission tomography/CT scan is generally not established as the initial evaluation unless there is concern about tumor resectability, suspicion of distant metastasis, or concern about aggressive histology.

\section{STAGING}

Salivary gland neoplasms are staged based on American Joint Committee on Cancer (AJCC) tumor-node-metastasis (TNM) staging (Table 1). The primary tumor $(\mathrm{T})$ is staged

Table 1: American Joint Committee on Cancer staging system for salivary gland malignancies

\begin{tabular}{|c|c|}
\hline \multicolumn{2}{|c|}{ Primary tumor $(T)$} \\
\hline Tx & Primary tumor cannot be assessed \\
\hline T0 & No evidence of primary tumor \\
\hline T1 & $\begin{array}{l}\text { Tumor } 2 \mathrm{~cm} \text { or less in greatest dimension without } \\
\text { extraparenchymal extension }\end{array}$ \\
\hline T2 & $\begin{array}{l}\text { Tumor more than } 2 \mathrm{~cm} \text { but no more than } 4 \mathrm{~cm} \text { in } \\
\text { greatest dimension without extra parenchymal extension }\end{array}$ \\
\hline T3 & $\begin{array}{l}\text { Tumor more than } 4 \mathrm{~cm} \text { and/or tumor having extra } \\
\text { parenchymal extension }\end{array}$ \\
\hline T4a & $\begin{array}{l}\text { Moderately advanced disease: Tumor invades skin, } \\
\text { mandible, ear canal, and/or facial nerve }\end{array}$ \\
\hline $\mathrm{T} 4 \mathrm{~b}$ & $\begin{array}{l}\text { Very advanced disease: Tumor invades skull base and/ } \\
\text { or pterygoid plates and/or encases carotid artery }\end{array}$ \\
\hline \multicolumn{2}{|r|}{ Regional lymph nodes $(N)$} \\
\hline $\mathrm{Nx}$ & Regional lymph nodes cannot be assessed \\
\hline NO & No regional lymph node metastasis \\
\hline N1 & $\begin{array}{l}\text { Metastasis in a single ipsilateral lymph node, } 3 \mathrm{~cm} \text { or } \\
\text { less in the greatest dimension }\end{array}$ \\
\hline N2a & $\begin{array}{l}\text { Metastasis in a single ipsilateral lymph node, more than } \\
3 \mathrm{~cm} \text { but no more than } 6 \mathrm{~cm} \text { in greatest dimension }\end{array}$ \\
\hline $\mathrm{N} 2 \mathrm{~b}$ & $\begin{array}{l}\text { Metastasis to multiple ipsilateral lymph nodes, more } \\
\text { than } 3 \mathrm{~cm} \text { but no more than } 6 \mathrm{~cm} \text { in greatest dimension }\end{array}$ \\
\hline N2c & $\begin{array}{l}\text { Metastasis in bilateral lymph nodes, none more than } 6 \\
\mathrm{~cm} \text { in greatest dimension }\end{array}$ \\
\hline N3 & $\begin{array}{l}\text { Metastasis in a lymph node, more than } 6 \mathrm{~cm} \text { in greatest } \\
\text { dimension }\end{array}$ \\
\hline \multicolumn{2}{|r|}{ Distant metastasis $(M)$} \\
\hline M0 & No distant metastasis \\
\hline M1 & Distant metastasis \\
\hline
\end{tabular}

based on the size and local extension of the tumor. Regional lymph node staging $(\mathrm{N})$ is based on the size and the number of lymph nodes involved. Presence of distant metastasis is denoted as M1. Overall cancer stage is derived from a combination of TNM categories (Table 2). ${ }^{19}$ Although AJCC classification can help predict prognosis, this is applied to an entire population and does not predict prognosis in an individual patient. In order to predict outcomes based on

Table 2: Stage grouping

\begin{tabular}{llll}
\hline Stage I & T1 & N0 & M0 \\
Stage II & T2 & N0 & M0 \\
Stage III & T3 & N0 & M0 \\
& T1 & N1 & M0 \\
Stage IVA & T2 & N1 & M0 \\
& T3 & N0 & M0 \\
& T4a & N1 & M0 \\
& T4a & N2 & M0 \\
& T1 & N2 & M0 \\
Stage IVB & T2 & N2 & M0 \\
Stage IVC & T3 & Any N & M0 \\
& T4a & N3 & M0 \\
& Any T & Any N & M1 \\
\hline
\end{tabular}


individual factors as opposed to a relative risk, a nomogram predicting the risk of recurrence of carcinomas of major salivary glands was developed based on age, grade, PNI, and nodal metastasis. ${ }^{20}$ Even though its predictive value needs to be further tested in a prospective cohort, it may facilitate counseling on prognosis and may help guide management and posttreatment surveillance.

\section{SURGICAL MANAGEMENT}

Surgery is the mainstay of management of resectable salivary gland tumors. The primary goal of surgery is complete removal of tumor with a cuff of histologically normal tissue with adequate margins for accurate diagnosis and local control, with preservation of nerve function when feasible. The tumor size, relationship to nerves, and degree of invasion into surrounding tissues determine the extent of surgery. For small tumors limited to the superficial lobe of parotid gland and sparing facial nerve, superficial parotidectomy with identification and preservation of facial nerve branches could be both diagnostic and therapeutic. Historically, surgical "enucleation" results in unacceptably high rate of recurrence and facial nerve paralysis. If the tumor involves the deep lobe of the parotid gland, a total parotidectomy is the procedure of choice to achieve adequate tumor clearance. If the facial nerve is encased by the tumor based on preoperative imaging or if preoperatively facial nerve function is impaired, radical parotidectomy involving removal of all parotid tissue as well as sacrifice of facial nerve is indicated. Extended radical parotidectomy is performed when salivary tumor invades adjacent structures, such as temporal bone, mandible, or skin. For tumors of submandibular and sublingual glands, level I neck dissection is preferred over a simple gland excision. If tumor involves adjacent structures resection may need to be extended to include the floor of the mouth muscles, adjacent nerves (lingual, hypoglossal, and marginal mandibular branch of facial nerve), and/or mandible. The surgical approach to the tumors of the minor salivary glands will depend of the site of the origin. Hard palate tumors may require maxillectomy. Tumors involving base of tongue may require paramedian mandibulotomy approach vs transoral robotic surgery approach when feasible.

Frozen section may be necessary to assist with intraoperative decision-making. Frozen section could confirm and/or clarify the diagnosis of malignancy and determine the need for concurrent neck dissection in a case of high-grade tumor, or to terminate surgery in the case of lymphoma. Malignancy should be confirmed prior to making the decision to sacrifice facial nerve. In addition, frozen section should be used to ensure proximal and distal control of the nerve resection prior to reconstruction.
Regional disease should be managed concurrently. For patients with clinically and/or pathologically positive nodes, modified radical neck dissection should be performed. The management of clinically N0 neck in salivary gland cancer remains a controversial topic. The overall risk of occult regional lymph node metastasis in salivary gland cancer is low and ranges from 14 to $20 \%{ }^{21}$ Some advocate elective neck treatment for every salivary gland cancer patient, while others propose elective selective neck dissection vs elective irradiation in high-risk cancer patients only. High-risk factors include high-grade tumors and advanced T stage $(>4 \mathrm{~cm}){ }^{22}$ and therefore, elective treatment should be considered in this group.

\section{ADJUVANT THERAPY}

Postoperative radiotherapy is beneficial in salivary gland tumors at a high risk of locoregional recurrence. The evidence to support postoperative radiotherapy is based on retrospective studies and, therefore, prognostic correlation is limited. ${ }^{23,24}$ Based on these studies, adjuvant radiotherapy is indicated in advanced stage disease (stages III-IV), for patients with regional lymph node metastasis and with adverse prognostic factors: Perineural invasion, vascular invasion, and close or positive margins. The radiation treatment portals should include the preoperative extent of primary tumor. Postoperative radiation treatment to the neck is recommended for positive regional metastasis. Recurrences in the contralateral neck are infrequent and, therefore, contralateral neck irradiation is generally not recommended. When a named nerve is involved, cranial nerve should be traced to the skull base and included in the treatment volume.

Three different sources of radiotherapy have been described in the postoperative management of salivary gland tumors: Photons, neutrons, and protons. Historically, postoperative radiation treatment was delivered by conformal wedged-pair beams to a dose of $60 \mathrm{~Gy}{ }^{25}$ Significant advances in the delivery of photon beam radiation therapy have been made over the last 30 years with the progression from the two-dimensional era to the three-dimensional era, and, finally, intensity-modulated radiation therapy (IMRT). Intensity-modulated radiation therapy allows improved tumor dose and normal tissue sparing resulting in reduced toxicity without compromising oncologic outcomes. Neutron beam therapy has been shown to be more effective in local control of unresectable salivary gland tumors as compared with conventional photon-based radiation treatment. However, severe treatment-related toxicities were higher in the experimental group. ${ }^{26}$ In addition, it is unclear how neutron beam outcomes will compare with IMRT. Most recently, proton beam radiotherapy (PBRT) has emerged as an attractive 
treatment modality in the management of salivary neoplasms. ${ }^{27}$ Due to its unique physical properties of proton energy deposition, PBRT lowers normal tissue exposure without compromising target coverage, thereby improving the therapeutic ratio. ${ }^{27}$

At this time, systemic chemotherapy has a limited role in the management of salivary malignancy. Clinical trials exploring the role of chemotherapy in the management of salivary gland carcinoma failed to show survival benefit. ${ }^{1}$ Chemotherapy, therefore, is reserved as a palliative measure for patients with symptoms and/or rapid disease progression. Cytotoxic chemotherapy is usually used as a first-line approach, which disrupts healthy and neoplastic tissues in a relatively nonspecific manner. More recently, therapies targeting specific molecular mechanisms, such as epidermal growth factor receptor, human epidermal growth factor receptor 2/neu, C-KIT, and vascular endothelial growth factor, have been investigated. ${ }^{28}$ None of these trials had yielded improvement in overall survival. Clearly, novel therapies are needed to improve outcomes for patients with locally advanced salivary malignancies.

\section{PERINEURAL INVASION}

Certain salivary tumors have the propensity to invade nerves. The most commonly involved nerves are facial nerve, trigeminal nerve, and their branches. High incidence rates of perineural invasion (PNI) are found in patients with adenoid cystic carcinoma and salivary ductal carcinoma, with lower rates in other salivary malignancies, such as mucoepidermoid and acinic cell carcinoma. ${ }^{1}$ Perineural invasion is defined as tumor invasion in, around, and through the nerves. ${ }^{29}$ Most cases of PNI are initially asymptomatic. Nerve infiltration may lead to significant morbidity due to pain, paralysis from motor nerve dysfunction, and numbness from sensory nerve dysfunction. Moreover, PNI has been identified as a significant poor prognostic indicator, heralding decreased survival, increased locoregional recurrence rates, and shorter time to recurrence. ${ }^{29}$ Due to better soft tissue definition, MRI with and without contrast is superior to CT scan in detecting PNI and delineating its extent. Characteristic features of PNI include widening of skull base foramina, enhancement of the nerve, and atrophy of corresponding muscles. In addition, intracranial extension of the tumor could be identified.

The surgical management of PNI requires careful planning in order to achieve adequate surgical margins. Nerve sacrifice is a topic of constant debate, especially if it leads to significant functional deficits. When do we sacrifice the nerve and when do we peel the tumor off the nerve? Most would agree that preoperatively nonfunctional nerve with gross evidence of PNI intraoperatively should be sacrificed, negative margin should be achieved, and repair/reanimation procedure should be performed if indicated. If the nerve is functioning preoperatively and there is no gross evidence of PNI intraoperatively, all effort should be made to preserve it. Nerve sacrifice will add little to the surgical margin, however, will result in significant morbidity. Moreover, sacrifice of the nerve will not avoid the need for radiation treatment. If the nerve is functioning preoperatively but neural invasion is noted at the time of surgery, nerve sacrifice is indicated.

When PNI is present in a pathological specimen, postoperative radiation fields should be adjusted to include the course of the nerve to the skull base. The role of conventional cytotoxic systemic therapies in the management of perineural spread is unclear. Currently, investigations are underway in order to better understand the mechanism of PNI and to develop novel therapeutics that target neurotrophic behavior rather than cell viability. These studies demonstrate that PNI results from reciprocal signaling between cancer, nerve, and stromal cells. ${ }^{30}$ Cells from the tumor microenvironment, such as fibroblast, macrophages, and Schwann cells, contribute to cancer cell invasion through modification of the extracellular matrix and paracrine regulation. ${ }^{31}$ Some of the described mechanisms of PNI overlap with the mechanisms that guide nerual degeneration-regeneration. In particular, signaling mechanism of glial cell-derived neurotrophic factor via RET/GFRalpha thyrosine kinase receptor is crucial in nerve development, ${ }^{32}$ but also has been described as a key mediator of cancer cell chemotaxis toward the nerve. ${ }^{30}$ Our understanding of the molecular mechanisms that drive PNI carries an opportunity for the development of new treatment modalities that will inhibit cancer cell dissemination along the nerves and treat neuropathic pain derived from neural tracking of cancer cells.

\section{CONCLUSION}

The behavior of malignant neoplasms of salivary gland origin varies from relatively indolent low-grade tumors to an aggressive disease with invasion of critical structures and widespread distant metastasis. Prior to making treatment decisions, the extent of the disease should be accurately delineated through history, physical exam, and imaging studies, including CT scan, MRI, and, in selected cases, PET/CT. Surgical extirpation is the primary modality of management of resectable tumors. Adjuvant treatment is achieved with radiation treatment in locally advanced cases. Chemotherapy is generally reserved to palliative cases. Better understanding of molecular mechanisms driving tumor progression and PNI should allow identification of novel therapeutic targets. 


\section{REFERENCES}

1. Laurie SA, Licitra L. Systemic therapy in palliative management of advanced salivary gland cancers. J Clin Oncol 2006 Jun;24(17):2673-2678.

2. Brandwein MS, Ferlito A, Bradley PJ, Hille JJ, Rinaldo A. Diagnosis and classification of salivary neoplasms: pathologic challenges and relevance to clinical outcomes. Acta Otolaryngol 2002 Oct;122(7):758-764.

3. Van der Laan BF, Baris G, Gregor RT, Hilgers FJ, Balm AJ. Radiation-induced tumors of the head and neck. J Laryngol Otol 1995 Apr;109(4):346-349.

4. Horn-Ross PL, Ljung BM, Morrow M. Environmental factors and the risk of salivary gland cancer. Epidemiology 1997 Jul;8(4):414-419.

5. Leclerc A, Martinez Cortes M, Gérin M, Luce D, Brugère J. Sino-nasal cancer and wood dust exposure: results from a case control study. Am J Epidemiol 1994 Aug;140(4):340-349.

6. Bonneterre V, Deschamps E, Persoons R, Bernardet C, Liaudy S, Maitre A, de Gaudemaris R. Sino-nasal cancer and exposure to leather dust. Occup Med(Lond) 2007 Sep;57(6):177-184.

7. Leivo I. Insights into a complex group of neoplastic disease: advances in histopathologic classification and molecular pathology of salivary gland cancer. Acta Oncol 2006;45(6):662-668.

8. Colmenero C, Patron M, Sierra I. Acinic cell carcinoma of the salivary glands. A review of 20 new cases. J Craniomaxillofac Surg 1991 Aug;19(6):260-266.

9. Savera AT, Sloman A, Huvos AG, Klimstra DS. Myopeithelial carcinoma of the salivary glands: a clinicopathologic study of 25 patients. Am J Surg Pathol 2000 Jun;24(6):761-774.

10. Bastakis JG. Staging of salivary gland neoplasms: role of histopathologic and molecular factors. Am J Surg 1994 Nov;168(5): 386-390.

11. Brandwein MS, Ivanov K, Wallace DI, Hille JJ, Wang B, Fahmy A, Bodian C, Urken ML, Gnepp DR, Huvos A, et al. Mucoepidermoid carcinoma: a clinicopathologic study of 80 patients with special reference to histopathological grading. Am J Surg Pathol 2001 Jul;25(7):835-845.

12. Bastakis JG, Luna MA. Histopathologic grading of salivary gland neoplasms: I. Mucoepidermoid carcinoma. Ann Otol Rhinol Laryngol 1990 Oct;99(10 Pt 1):835-838.

13. Bastakis JG, Luna MA, el-Naggar AK. Histopathologic grading of salivary gland neoplasms: II. Acinic cell carcinoma. Ann Otol Rhinol Laryngol 1990 Nov;99(11):929-933.

14. Bastakis JG, Luna MA, el-Naggar AK. Histopathologic grading of salivary gland neoplasms: III. Adenoid cystic carcinoma. Ann Otol Rhinol Laryngol 1990 Dec;99(12):1007-1009.

15. Spiro RH, Huvos AG, Strong EW. Cancer of the parotid gland. A clinicopathologic study of 288 primary cases. Am J Surg 1975 Oct;130(4):452-459.

16. Cohen EG, Patel SG, Lin O, Boyle JO, Kraus DH, Singh B, Wong RJ, Shah JP, Shaha AR. Fine-needle aspiration biopsy of salivary gland lesions in a selected patient population. Arch Otolatyngol Head Neck Surg 2004 Jun;130(6):773-778.

17. Bartes S, Talbot M, DiTomasso J, Everts EC, Anderson PE, Wax MK, Cohen JI. The relative value of FNA and imaging in the preoperative evaluation of parotid masses. Head Neck 2000 Dec;22(8):781-786.

18. McGuit WF, Keyes JW Jr, Greven KM, Williams DW 3rd, Watson NE Jr, Cappellari JO. Preoperative identification if benign versus malignant parotid masses: a comparative study including positron emission tomography. Laryngoscope 1995 Jun;105(6):579-584.
19. Edge, S.; Byrd, DR.; Compton, CC.; Fritz, AG.; Greene, FL.; Trotti, A.; editors. AJCC cancer staging manual. 7th ed. Chicago (IL): Springer; 2010.

20. Ali S, Palmer FL, Yu C, DiLorenzo M, Shah JP, Kattan MW, Patel SG, Ganly I. A Predictive nomogram for recurrence of carcinoma of the major salivary glands. JAMA Otolaryngol Head Neck Surg 2013 Jul;139(7):698-705.

21. Stennert E, Kisner D, Jungehuelsing M, Guntinas-Lichius O, Schröder U, Eckel HE, Klussmann JP. High incidence of lymph node metastasis in major salivary gland cancer. Arch Otolaryngol Head Neck Surg 2003 Jul;127(7):720-723.

22. Armstrong JG, Harrison LB, Thaler HT, Friedlander-Klar H, Fass DE, Zelefsky MJ, Shah JP, Strong EW, Spiro RH. The indications for elective treatment of the neck in cancer of major salivary glands. Cancer 1992 Feb;69(3):615-619.

23. Armstrong JG, Harrison LB, Spiro RH, Fass DE, Strong EW, Fuks ZY. Malignant tumors of major salivary gland origin. A matched pair analysis of the role of combined surgery and post-operative radiotherapy. Arch Otolaryngol Head Neck Surg 1990 Mar;116(3):290-293.

24. Terhhard $\mathrm{CH}$, Lubsen $\mathrm{H}$, Van der Tweel I, Hilgers FJ, Eijkenboom WM, Marres HA, Tjho-Heslinga RE, de Jong JM, Roodenburg JL, Dutch Head and Neck Oncology Cooperative Group. Salivary gland carcinoma: independent prognostic factors for locoregional control, distant metastasis, and overall survival: results of the Head and Neck Oncology Cooperative Group. Head Neck 2004 Aug;26(8):681-692.

25. Ferlito A, Shaha AR, Rinaldo A, Mondin V. Management of clinically negative cervical lymph nodes in oatients with malignant neoplasms of parotid gland. ORL J Otolaryngol Relat Spec 2001 May-Jun;63(3):123-126.

26. Laramore GE, Krall JM, Griffith TW, Duncan W, Ritcher MP, Saroja KR, Maor MH, Davis LW. Neutron versus photon irradiation for unresectable salivary gland tumors: final report of an RTOGMRC randomized clinical trial. RTOG Medical Research Council. Int J Radiat Oncol Biol Phys 1993 Sep 30;27(2):235-240.

27. Romesser PB, Cahlon O, Scher E, Zhou Y, Berry SL, Rybkin A, Sine KM, Tang S, Sherman EJ, Wong R, Lee NY. Proton beam radiation therapy results in significantly reduced toxicity compared with intensity-modulated radiation therapy for head and neck tumors that require ipsilateral irradiation. Radiother Oncol 2016 Feb;118(2):286-292.

28. Griffith CC, Schmitt AC, Little JL, Magliocca KR. New developments in salivary gland pathology: clinically useful ancillary testing and new potentially targetable molecular alterations. Arch Pathol Lab Med 2017 Mar;141(3):381-395.

29. Liebeg C, Ayala G, Wilks JA, Berger DH, Albo D. Perineural invasion in cancer: a review of the literature. Cancer 2009 Aug;115(15):3379-3391.

30. Gil Z, Cavel O, Kelly K, Brader P, Rein A, Gao SP, Carlson DL, Shah JP, Fong Y, Wong RJ. Paracrine regulation of pancreatic cancer cell invasion by peripheral nerves. J Natl Cancer Inst 2010 Jan;102(2):107-118.

31. Deborde S, Omelchenko T, Lyubchik A, Zhou Y, He S, McNamara WF, Chernichenko N, Lee SY, Barajas F, Chen CH, et al. Schwann cells induce cancer cell dispersion and invasion. J Clin Invest2016 Apr;126(4):1538-1554.

32. Ledda F, Paratcha G, Ibáñez C. Target-derived GFRalpha1 as an attractive guidance signal for developing sensory and sympathetic axons via activation of Cdk5. Neuron 2002 Oct;36(3):387-401. 